\title{
Women living with chronic illness experienced transition that involved stages of distress and a quest for ordinariness
}

\author{
Kralik D. The quest for ordinariness: transition experienced by midlife women living with chronic illness.J Adv Nurs \\ 2002;39:146-54.
}

\section{QUESTION: What is the meaning of living with chronic illness for midlife women?}

Design

A feminist participatory research design.

\section{Setting}

No fixed setting because of data collection method (email and letter writing).

\section{Participants}

81 women aged $30-50$ years (mean age 44 y) who identified themselves as living with adult onset chronic illness. Women were from Australia, New Zealand, Samoa, North America, and the United Kingdom.

\section{Methods}

Through email and letter writing spanning 12 months, women told their stories about their experiences of living with chronic illness. The frequency of correspondence varied at the discretion of each participant. Correspondence data from participants were thematically analysed. A subset of engaged participants was actively involved in developing constructs and themes by offering validation, clarification, and interpretation.

\section{Main findings}

2 major themes emerged: extraordinariness, which represented the phase of turmoil and distress that occurred when the women first experienced their chronic illness; and ordinariness, which occurred over time as the women made the transition of incorporating chronic illness into their lives. The transition from extraordinariness to ordinariness and sometimes back again affected the stability of everyday life. The theme of extraordinariness included 2 major constructs. How quickly life changes described women's experiences of learning they had chronic illness. The diagnosis of a chronic illness was a profound and life altering event that resulted in physical and emotional disturbances. Extraordinariness: confronting life with illness described women's feelings of alienation from familiar life and loss of control over life circumstances. These feelings decreased self esteem and made women feel vulnerable.

The theme of ordinariness included 2 major constructs. The illness experience as transforming represented the dynamic state (the many changes) that women experienced, which led to increased self awareness and the seeking of empowerment. Ordinariness: reconstructing life with illness represented the process of learning, making choices, and identifying changes that were needed so that illness could have a place in the women's lives. Achieving ordinariness allowed women to regain a sense of balance and control over their lives.

\section{Conclusions}

Women living with adult onset chronic illness described confrontation with their illness as a complex and profound life event, which involved an "extraordinary" phase of turmoil and distress and an "ordinary" phase of learning to incorporate chronic illness into their lives. Living with chronic illness involved a dynamic internalised transition between extraordinariness and ordinariness to create stability and meaning in every day life. Striving for ordinariness helped women to regain a sense of balance and control over their lives.
Source of funding: no external funding.

For correspondence: Dr D Kralik, Royal District Nursing

Service Research Unit, Flinders University of South Australia, Glenside, Australia. kralik@bigpond.com

\section{COMMENTARY}

Describing the experience of midlife women living with chronic illness as a quest for ordinariness, Kralik's research can be linked to research on the concept of normalisation. Originally used in the context of deinstitutionalising children and adults, this concept has evolved to describe a person's or family's response to illness or disability in various chronic illness contexts. ${ }^{1}$ The idea that living with a chronic illness involves processes of transition and transformation is also congruent with the emerging understanding of the experience of recovery after treatment for breast cancer. ${ }^{2}$

Strengths of Kralik's study design include the large number of participants (81 women) and the creative method of data collection over a 1 year period. Having some participants actively contributing to the process of data analysis and thematic development adds to the credibility of the findings. A possible weakness might be that participants self identified themselves as living with chronic illness. Although this honours the feminist perspective of this study, it may raise questions about the applicability of the findings. However, it also emphasises the importance of the nurse's understanding of the individual illness experience regardless of diagnosis.

Findings of this study are clinically relevant in many settings. Nurses who work with women who live with chronic fatigue syndrome, diabetes, multiple sclerosis, or cancer, for example, are reminded that the profound life altering effect of such a diagnosis does not dissipate quickly or easily. When nurses recognise the power that "being normal" holds, they may listen more sensitively to women's stories of the struggle with being different. Helping them identify when their attempts to conform to society's expectations threaten their self esteem may help women to shift perspective and gain more control of their situation. At the same time, by helping women to actively make their own choices so that they can live well with their illness and encouraging them in their progress, nurses can facilitate the transition towards the "ordinariness" that women with chronic illness seek.

Chris Emery, RN, MSN, CON(C) Clinical Nurse Specialist, Acute Palliative Care Fraser Health Authority New Westminster, British Columbia, Canada

1 Robinson CA. Managing life with a chronic condition: the story of normalization. Qual Health Res 1993;3:6-28.

2 Emery C. Moving on: the post-treatment experience of women and families with breast cancer. Unpublished master's thesis, University of British Columbia, Vancouver, British Columbia, 2002. 